\title{
Effectiveness of a "Planned Teaching Programme"(PTP) on Knowledge Related to Reproductive Tract Infections Among Rural Women
}

\author{
Alka Chauhan, Divya Chawla, Garima Saini, Himani Rawat, Kuldeep Pundir* \\ Laxmi kumar** Piyalee Benjamin *** \\ * $4^{\text {th }}$ year B.Sc. Nursing Students, Himalayan College of Nursing, HIHT, Dehradun \\ **Lecturer, Obstetrics \& Gynaecological Nursing, Himalayan College of Nursing, HIHT, Dehradun \\ ***Nursing Tutor, Himalayan College of Nursing, HIHT, Dehradun.
}

\begin{abstract}
The most important period in the life span of women is the reproductive period, which extends from menarche to menopause. Reproductive tract infections are endemic in developing countries and entail a heavy toll on women. If untreated reproductive tract infections can lead to adverse health outcomes such as infertility, ectopic pregnancy and increased vulnerability to transmission of HIV. Quantitative evaluative approach was used and research design was one group pre-test post-test design. Sample were women of reproductive age group, sample size was 40 and sample technique was random sampling, setting for the study was Thano, Dehradun, tool used were self prepared knowledge questionnaire related to reproductive tract infections. Majority (80\%) of the subjects were between 15 to 30 years. Majority (77.5\%) of the subjects were married, majority of (77.5\%) subjects had educational status up to higher secondary and above, majority of (55\%) of the subjects have family monthly income above Rs 6,000, majority (65\%) of the subjects were from nuclear family, majority of (57.5\%) of the subjects had moderate pre-test knowledge score regarding reproductive tract infection. The mean of post-test knowledge score was higher than mean of pre-test knowledge score. Age, educational status and marital status had significant association with pre test knowledge score. Study showed that planned teaching programme regarding reproductive tract infections was effective in increasing women knowledge level. There was a significant association of knowledge level with age, educational status and marital status.
\end{abstract}

Keywords: Assess, Effectiveness, Knowledge, Planned teaching program, Reproductive tract infection.

\section{Introduction}

Diseases are of many types such as communicable and non communicable, curable and incurable and so on- W.H.O. (1948).Among them reproductive tract infections is one of the disease. Reproductive tract infections are endemic in developing countries and entail a heavy toll on women. If untreated reproductive tract infections can lead to .adverse health outcomes such as infertility, ectopic pregnancy and increased vulnerability to transmission of HIV. It is also associated with adverse pregnancy outcomes. 1

Reproductive tract infections are recognized as public health problem and rank second as the cause of healthy life lost among women of reproductive age after maternal morbidity and mortality in developing countries. In addition, the presence of reproductive tract infections is often associated with an increased risk for acquiring and transmitting HIV in much different population.2

\subsection{Need of Study:}

Reproductive tract infections generally seen as a silent epidemic is one of the major public health problems causing a significant proportion of gynecological morbidity and maternal mortality in developing countries. Studies on women in developing countries have found reproductive tract infection prevalence rates ranging from 52 to 92 percent. With an annual incident of 340 million STI cases globally and many more endogenous and iatrogenic infections, reproductive tract infections are considered as global public health issue. In resources poor countries, where 75 to 85 percent of these new cases occur, reproductive tract infections are among the five most common health problems leading to contact with health system.3

The global burden of reproductive tract infection enormous and of a major public health concern, particularly in developing countries where reproductive tract infections are endemic. Reproductive tract infections, excluding HIV constitute the second major cause of disease burden in young adult women in developing countries. 4

Studies conducted in India indicate high prevalence of reproductive tract infections revealing a prevalence varying from 19 to 71 percent. As per the survey conducted by the government of India during 1999, involving 252 districts, the prevalence rate of reproductive tract infections in India was 28.8 percent. 
Reproductive tract infection is slightly more common among rural women (30 percent) compare to urban (26 percent) also the prevalence rate is lower for educated women 31 percent among illiterate compared to 22 percent among women who have completed 10th grade or high school level.5

In India the prevalence of reproductive tract infection is very high due to silent epidemic. The low status of women in parts of India makes women suffer in silence or even feel too ashamed to seek treatment. Hence, there is need to assess women's level of knowledge regarding reproductive tract infection through study.6

\subsection{Statement of Problem:}

A study to assess the effectiveness of planned teaching programme on Reproductive Tract Infections among women in selected rural community of Uttarakhand.

\subsection{Objectives:}

- To assess the existing level of knowledge of women regarding reproductive tract infections.

- To assess the effectiveness of planned teaching programme on reproductive tract infections by comparing the pre-test and post-test knowledge score.

- To find out the association between pre-test knowledge score and selected demographic variables.

1.5 Hypothesis:

$\mathbf{H}_{1}$ : There is a significance difference between pretest and post test level of knowledge.

H2: There is a significant association between the post test knowledge score and demographic variables at the level of $\mathrm{P}<0.05$

\section{MeTHODOLOGY}

The research design used in this study was pre-experimental one group pretest post test design. The study was conducted at community health center in Uttarakhand, INDIA. The sample of 40 women of reproductive age group was selected by using convenient sampling technique. The tool used for the study was the structured knowledge questionnaire consisting of section A (Socio- demographic variables such as age, educational status, marital status, type of family and monthly family income Section B (consisting of 30 items related to Knowledge regarding reproductive tract infections in five aspects i.e anatomy \& physiology of reproductive tract, syphilis, gonorrhea, vaginosis, candidiasis). The content validity of the tool was ensured by giving the tool to experts in the field of Obstetrics and Gynecology, \& Community health nursing of Himalayan College of nursing.

\section{RESULTS AND FINDINGS}

3.1 Related to Socio-Demographic Profile of women of reproductive age group: Table No.1: Socio-Demographic Profile of the women

$\mathbf{N}=\mathbf{4 0}$

\begin{tabular}{lcc}
\hline Sample character & frequency & Percentage \\
\hline & & \\
AGE IN YEARS & 32 & $80 \%$ \\
$\quad$ 15-30 & 8 & $20 \%$ \\
31-45 & 31 & $77.5 \%$ \\
MARITAL STATUS & 9 & $22.5 \%$ \\
$\quad$ Married & & \\
$\quad$ Unmarried & 9 & $22.5 \%$ \\
EDUCATIONAL STATUS & 31 & $77.5 \%$ \\
$\quad$ No formal education - primary education & & \\
Secondary \& above & 18 & $55 \%$ \\
MONTHLY FAMILY INCOME & 22 & $35 \%$ \\
Up to Rs. 6,000 & & $65 \%$ \\
Above Rs. 6,000 & 14 & \\
TYPE OF FAMILY & 26 & \\
Nuclear & & \\
Joint &
\end{tabular}

Description of table no.1:- This table shows that majority 32(80\%) of the samples were in the age group of 1530 years. One third $31(77.5 \%)$ of the samples were married. Majority $31(77.5 \%)$ of the samples have 
educational status secondary and above. Majority $22(55 \%)$ of the samples were having monthly family income above Rs. 6,000. Majority 26(65\%) of the samples were belonged to joint family.

\subsection{Analysis of area wise knowledge score of women obtained in pretest and posttest}

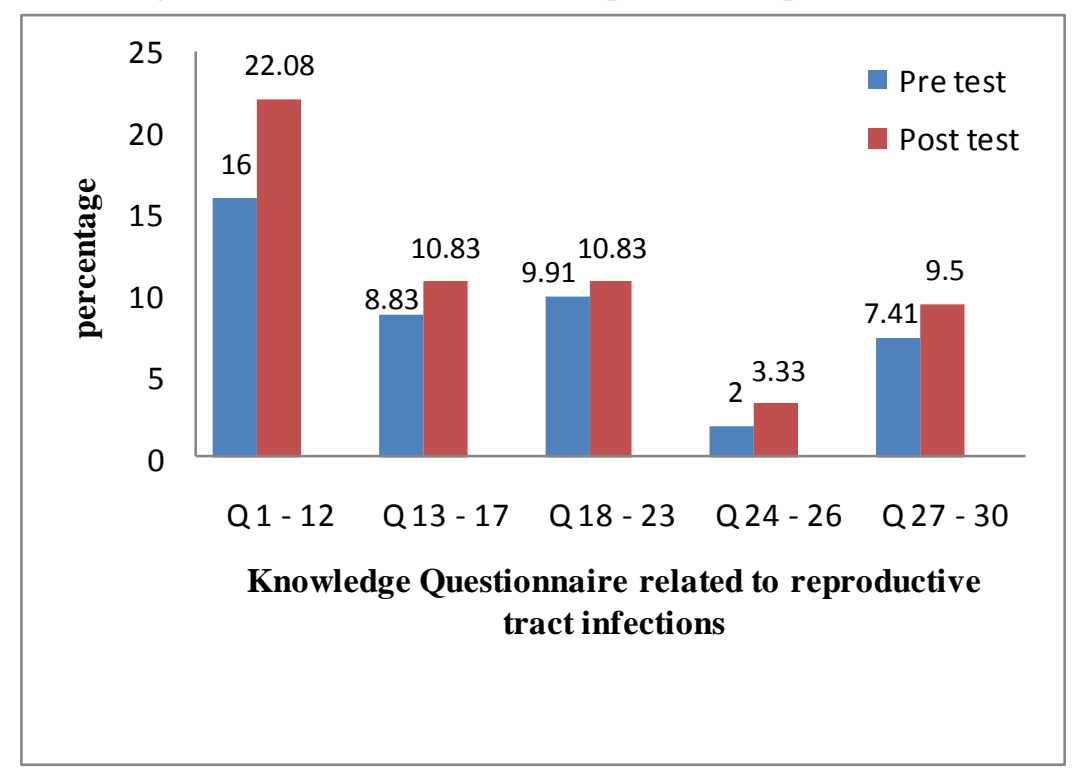

Figure no.1 shows Knowledge Questionnaire related to reproductive tract infections

Data presented in figure no.1 that mean of pretest and posttest knowledge related to different areas

(Q1-12 Knowledge related to anatomy \& physiology of reproductive tract, Q13-17 Knowledge related to syphilis, Q18-23 Knowledge related to Gonorrhea, Q24-26 Knowledge related to vaginosis, Q27-30 Knowledge related to Candidiasis). So it is interpreted that planned teaching programme was effective to increase knowledge of women regarding reproductive tract infections.

Table No.2 Pretest and posttest knowledge of women related to reproductive tract infections.

\begin{tabular}{lccc}
\hline Knowledge score & Mean \pm S.D & Mean difference & 't'value \\
\hline Pretest & $13.25 \pm 3.71$ & 3.67 & $6.23^{*}$ \\
Posttest & $16.93 \pm 3.70$ & & \\
\hline * significant at $\mathrm{P}<0.05$ level & & $\mathrm{df}(38)$
\end{tabular}

Table no. 2 shows that the mean of post-test knowledge score (16.93) of the women was higher than that of the mean of pre-test knowledge score (13.25).The scores predicted that the significant difference between the mean of pre-test and post-test at $p<0.05$ level. Hence, it is interpreted that planned teaching programme regarding reproductive tract infections was effective in increasing the knowledge of women.

Table No.3 Association between pre- test knowledge score and selected demographic variables.

\begin{tabular}{|c|c|c|}
\hline Demographic variables & Knowledge score & 't' value \\
\hline \multicolumn{3}{|l|}{ AGE IN YEARS } \\
\hline $15-30$ & 14.28 & $2.43^{*}$ \\
\hline $31-45$ & 9.13 & \\
\hline \multicolumn{3}{|l|}{ EDUCATION } \\
\hline Formal education- primary education & 6.33 & $8.71 *$ \\
\hline Secondary $\&$ above & 15.26 & \\
\hline \multicolumn{3}{|l|}{ MARITAL STATUS } \\
\hline Married & 12.32 & $2.61 *$ \\
\hline Unmarried & 16.44 & \\
\hline
\end{tabular}

$\mathrm{df}=38$ 
Independent ' $\mathrm{t}$ ' test at significant at $\mathrm{p}<0.05$ level

Table no. 3 shows that mean pretest knowledge score for age group 15-30 is 14.28 which is higher than mean for age group 31-45 years of age. Mean pretest knowledge score for secondary \& above education is 15.26 is higher than formal to primary education. Regarding marital status mean pretest knowledge score of unmarried is 16.44 which is higher than married. The calculated value is higher than table value. Hence, it is interpreted that there is an association between demographic variables with pretest knowledge score.

\section{Nursing services:-}

\section{NURSING IMPLICATIONS}

The study has revealed that maximum women have average knowledge regarding reproductive tract infection.

- Nurses can take active part in educating women regarding reproductive tract infection.

- Nursing personal can help the women by providing knowledge regarding reproductive tract infection, so that women can be prevented from it.

- Nurses can educate the women through exhibition and role play.

Nursing Administration: - Nursing has become a complex and highly varied descriptive with the rapid growing, well developed and well documented scientific and humanistic knowledge base.

- Nursing administration should provide necessary facilities to nursing staff and encourage use of cost effective audio visual aids and material, models in client teaching.

- Continue nursing education can be organized by nursing personal to educate them regarding

Nursing Education: reproductive tract infection so that nurses can educate women.

Nursing student should be educated about the prevention of reproductive tract infection, so that they can educate women regarding reproductive tract infection in community and clinical area.

\section{Nursing Research: -}

There is the need to conduct further research studies in the field related to knowledge, attitude and practice regarding reproductive tract infections.

\section{CONCLUSION}

Based on the findings of the study, it is concluded that most of the women had very good knowledge regarding Reproductive tract infections after implementation of Planned Teaching Programme.

The following conclusions were drawn on the basis of the present study

1. The findings showed that out of 40 women $\mathbf{1 3}$ had good level of knowledge in the pre-test knowledge score on the reproductive tract infections. The mean post-test percentage score and the gain scores in all areas were found to be significantly high, the maximum gain being in the area of anatomy and physiology of reproductive tract and lowest in the area of candidiasis.

2. From the findings of the study, it can be concluded that the administered a Planned teaching programme was effective as a method to improve the knowledge of women regarding reproductive tract infections.

\section{ACKNOWLEDGEMENT}

Gratitude can never be expressed in words but this is only deep perception that makes the words to flow from one's inner heart.

A research project can never become successful without the coordinated efforts of members of the team. I have been very fortunate indeed to have valuable guidance of our advisors and experts.

First and foremost, I would like to humbly thank almighty God for his divine interventions in my life without which I would not have been able to make this study.

We give our sincere thanks to Mrs. Sanchita Pugazhendi (Principal and HOD, Community Department), Himalayan College of Nursing for her guidance and supervision provided to us in conducting the present research study. We give our heart full thanks to Mrs. Kamli Prakash (Vice Principal) for her constant support and encouragement. We acknowledge our sincere thanks to Mrs. Laxmi Kumar \& Mrs. Piyalee Benjamin who has supported and helped us to sustain enthusiasm in completing this research study.

\section{REFERENCES}

[1]. Kabiru KA, Adewunmi AA, Akinlusi FM, Akinola OI.Female reproductive tract infections:understanding and care seeking behavior among women of reproductive age in Lagos, Nigeria.BMC women's Health[serial on the internet]2010Nov12[cited on 2012Jan15];10[about 12 pages] available from: http://www.ncbi.nih.gov/pmc/articles/

[2]. Jindal N, Aggarwal A, Gill P, Sabharwal B, Sheevani BB.Community based study on reproductive tract infection,including sexually transmitted infection, among the rural population of Punjab, India. Indian J Community Med[serial on the internet].2009Oct[cited on 2012Jan13].34(4):[about 8 screens].available from: http://www.ijcm.org 
[3]. Prasad JH, Abraham S, Kurz KN, George V, Lalitha MK, John R et al.Reproductive tract infections among young married women in Tamil Nadu, India. [serial on internet].2005June[cited on 2012Jan15];31(2);[about 10 screens].available from: http://www.ncbi.nlm.nih.gov/pubmed/15982948

[4]. Prashar A, Gupta BP, Bharadwaj Ak,Sarin R. Prevalence of reproductive tract infection among women of reproductive age group in Shimla.Indian J Community Med[serial on internet]2006Jan[citad on 2012Jan25]:31(1):[about 4 pages]. available from http://www.Indmedica.com/journals.php?journalid=7\&issueid=80\&articleid=1061\&action=article

[5]. Dawn A, Biswas R.Reproductive tract infection:An experience in rural West Bengal. Indian J Public Health.[serial on the internet]2000Aug[cited on 2012Jan27]:7(1):[abut 3 screens].available from :http://www.ncbi.nlm.nih.gov/pmc/article /PMC2851660

[6]. Hemlatha B.S..Women's knowledge on reproductive tract infections in selected area of Raichur.The Nursing Journal Of India.2008August;xcix(8):180-2

\section{OTHER REFERENCES}

[7]. Shrivastav L. reproductive tract infection among women of rural community in Mewat.Journal Of Health Management[serial on the internet].20100ct12[cited on 2012Jan15];12(4):[about 20 pages] available from: http://www.jhm.sagepub.com/content /12/4 /

[8]. Sharma S, Gupta BP.The prevalence of reproductive tract infections and sexually transmitted disease among married women in the reproductive age group in a rural area. Indian J Community Med[serial on the internet].2009Jan[cited on 2012Jan19]:34(1):[about 8 screens].available from: http://www.nbi.nlm.nih.gov/pmc/articles/PMC/2763657

[9]. Hurong NM, Kurtzhals J, Thuy DT, Rasch V. Reproductive tract infections in women seeking abortion in Vietnam.BMC women's Health[serial on the internet]:2009Jan29[cited on 2012Jan18];9:[about 12 screens].available from:http://www.biomedcentral.com11472-6874/9/1

[10]. Kosambiya JK, Desai VK, Bhardwaj P,Chakraborty T.RTI/STI prevalence among urban and ural women of Surat:A community based study.Indian Journal Of Sexually Transmitted Diseases anb AIDS[serial on the internet].2009[cited on 2012Jan17];30(2):[about 5 pages]available from:http://www.ijstd.org/text.asp?2009/30/2/89/62764

[11]. Li C,Han HR, Lee ZE, Lee Y, Kim MT.Knowledge,behavior and prevalence of reproductive tract infections:A descriptive study on rural women in Hunchun, China. Asian Nursing Research[serial on the internet].2010Aug31[cited on2012Jan19];4(3):[about 7 screens].available from:http://www.kan.or.kr/new/kor/sub3/filedata-anr/2021003/122pdf.

[12]. Lan PT, Lundborg CS, Phuc HD,Sihavong A, Unemo M, Chuc NT, Morgen T et al.Reproductive tract infections including STI: A population based study on women of reproductive age in a rural district of Vietnam.Sex Transm Infect. [serial on the internet]2008April[cited on 2012Jan20]:84(2):[about 7 pages].available from:http://www.ncbi.nlm.nih.gov/pnc/articles/PMC2822203

[13]. GO FV, Quan MV, Celentano DD, Moulton LH, Jenilman JM.Prevalence and risk factor for reproductive tract infection among women in rural Vietnam.SouthEast Asian J Trop Med Public Health.[serial pn the internet]2006Jan[cited on2012Jan29]:37(1):[about 4 pages]available from:http://www.tm.manidol ac th/sameo/2006-37-11-30-3661.pdf

[14]. Aggarwal AK,kumar R,gupta V, Sharma M. Community based study of reproductive tract infections on ever married women of reproductive age in a rural area of hariyana, Indian. J commun dis[serial on the internet].1999dec[cited on 2012jan30]:31(4): [about 6 pages] available from http://www.ncbi.nlm.nih.gov/pubmed/10937298. 